\title{
MANAGING THE KNOWLEDGE OF THE ORGANIZATION
}

\author{
Martin Stenberg \\ Principal Lecturer, Haaga Polytechnic, Helsinki, Finland; martin.stenberg@mstcons.com
}

\begin{abstract}
One of the most influential areas of research that has emerged in the field of Information Systems in the last decade is that of Knowledge Management. This was a natural development arising from work in disciplines such as organization studies, cognitive science and informatics, which all inspired the concepts of knowledge capture and knowledge-based systems. The purpose of this paper is to map the existing research, to describe what is meant by 'knowledge' and the processes of 'knowing', as well as organizational memory, and the contexts in which they occur.
\end{abstract}

\section{INTRODUCTION}

Knowledge management has become widely recognized as one of the most important contemporary research themes. Knowledge has been investigated from the viewpoint of learning (Nonaka and Konno 1998; Crossan et al 1999; Cook and Brown 1999; Kasl et al. 1997; Stenberg 2000; Kim 1993, Kolb 1984), society (Stehr 1994; Castells 1996) and technology (Masuda 1981; Robey et al. 2000; Orlikowsky 2000; Johannessen et al 2001). Peter Drucker (1993) has written about knowledge applied to tools, products and processes (embodied knowledge), knowledge applied to human work (embedded knowledge) and knowledge applied to itself (embrained and encultured knowledge). Reich (1991) noted that knowledge is supporting new forms of organizations based on networks, partnership and contacts (embrained knowledge). Theoretical views about organizations seem also to indicate that there are competitive advantages for a company offered by cooperative social contexts which are conductive to the creation, 
exploring, acquisition, transferring, integrating and coordinating knowledge distributed among employees, teams, business units and partners (Ghoshal and Moran 1996). It has also been suggested that sources of competitive advantage have been based on economies of expertise that are derived by leveraging knowledge in the organization both in intra- and interorganizational relationships (Subramani and Venkatraman 2003; Nonaka and Konno 1998; Yli-Renko 1999; Pirttilä 1997). Sambamurthy and Subramani (2005) also discuss knowledge research as comprising problems of knowledge coordination, transfer and reuse. There is also theoretical interest aroused by the many and confusing details of the earlier concepts (such as tacit vs explicit; process and element; individual and organizational).

Thus the subject is partly seen as organizational and operational research when it covers core processes and competitive advantages, but also as educational research because of the principal characteristic of learning, which is to acquire knowledge. Furthermore, in considering knowledge assets and the processes through which knowledge is acquired, used and created, Information Systems (technology and applications) are also seen as having an essential role in providing tools facilitating the use of knowledge and speeding knowledge processes (Robey et al. 2000; Orlikowsky 2000; Johannessen et al 2001).

There are a number of essential and common elements present in the studies. First, several of them focus on the processes employed to acquire, use, benefit and share knowledge (Huber 1990; Crossan et al. 1999; Nonaka and Konno 1998; Kim 1993), or recommend that we speak about the act of knowing rather than about knowledge itself (Blackler 1995; Robey et al. 2000 ), or of combining knowledge into a tool in knowing processes (Cook and Brown 1999).

Second, when knowledge is used in different situations by several actors, it appears to switch between tacit and explicit knowledge (Nonaka and Konno 1998) and create a Social Learning cycle (Boisot 1998). In this, it moves between the abstract and the concrete, codified and uncodified and diffused and undiffused and also between different kinds of images (Blackler 1995).

There are also a number of studies discussing challenges and roles of IS (information technology, applications and data communication) a technological and intermediating tool in knowledge processes (Robey et al. 2000; Daft and Lengel 1986; Andreu and Ciborra 1996; Johannessen et al. 2001; Zuboff 1988). 
Organizational memory is often mentioned as a development stage of organizational learning. Organizational memory consists of information acquisition, retention facilities and information retrieval. (Walsh and Ungson 1991)

The significance of the researching unit is important. In the present author's earlier study, prospective knowledge issues have mainly been covered quite theoretically and from a viewpoint focusing often on information-intensive companies (Stenberg 2000). The organization in which the author is currently conducting research is a large logistics company with a large amount of daily business events that provide an interesting and operational context for knowledge sharing.

The present paper will first review the background and common images of "knowing", collecting elements of knowing from a review of the literature. A case study (single case, multiple units) will then be presented, based on interviews of top and middle managers as well as employees of a Finnish logistics company. This study will provide the elements for a sharing model of information and knowledge issues and processes in the company.

\section{ISSUES AND ELEMENTS OF KNOWING}

\subsection{Knowledge and Knowing Levels}

Information has been noted as a broad and somewhat confusing concept (Sweiby 1997, pp 42-43). It has also been described as a separate subelement of knowledge associated with specific requirements of success, thoroughness and truthfulness, and has been defined as stored knowledge that is usable by those having access to the storage medium (Feinman 1976) or as any physical form of representation or surrogate of knowledge, and in particular thought used for communication (Farrandane 1979). Information can also lose its value, becoming commonplace and obsolete and even meaningless (Sweiby 1977, 40; Chen \& Edgington 2005, 287). Thus, information seems to be a part of knowledge.

Knowledge itself is more like an event (Luhmann 1995). Research is an important source of the information used to create new knowledge (Fahey \& Prusak 1998, p 727). It is also suggested that information becomes 
knowledge when it is exploited in decision-making processes, thus being inseparable from thinking and acting (Fahey \& Prusak 1998, 269).

Explicit knowledge that has been committed to a medium becomes information (Hildreth and Kimble 2002).

Tacit knowledge is a tool or an aid to action. It is not explicitly known or learned and it becomes realized in the context of the group's work, where performing a specific task requires interaction between (tacit) knowledge and present activity. (Crossan et al. 1999; Cook and Brown 1999.)

According to Robillard (1999), knowledge refers to a permanent structure of information stored in memory. For Nonaka (1994), knowledge is a specific entity formed in the mind of an individual, and is conceptually distinct from material and technologies.

Organizational skills are made up of a complex mix of interpersonal, technological and socio-structural factors (Blackler 1995, 1025). According to Blackler (1995) there are five images of knowledge: embrained, embodied, embedded, encultured and encoded.

Knowledge is a fundamental element of the process of knowing. Even though there are conflicting views regarding the definition of knowledge (Nonaka 1994; Cook and Brown 1999; Cook and Brown 1999; Wilson 2002; Hildreth and Kimble 2002), it is possible to extract some common elements regarding information and knowledge; both tacit and explicit. The literature recognizes three levels of knowing: individual, team and organizational.

Generally, the concept of knowing has been used to distinguish knowledge (as a tool) from knowing (as a process). Knowledge is something that is possessed (rules, concepts, procedures) being abstract, static, necessary and used in action. Knowing is an essential part of action or practice (dynamic, concrete or relational). Knowledge gives shape and discipline to knowing. Knowing requires present activity and so is understood as part of concrete and dynamic human action. (Cook and Brown 1999.)

Barney (1991, pp 101-103) defines among a firm's resources all assets and capabilities controlled by itself enhancing and improving its efficiency and effectiveness, including organizational processes, knowledge and information. A resource can become a sustained competitive advantage if it 
is valuable in exploiting opportunities, rare, strategic, imperfectly imitable and cannot be equivalently substituted.

Holsapple and Joshi (2001) consider the main organizational resources to be financial, material, human and knowledge. According to them, productive use of knowledge resources depends on the application of knowledge manipulation skills such as through a decision support system or by exercising a kind of human resource. (ibid. 43.) Dependencies are based on organization's presence and existence.

Ichijo et al. (1998) identifies five different "knowledge enablers", which are organizational mechanisms for intentionally and consistently developing knowledge in organizations.

Ichijo et al (1998) mentioning that to have a knowledge-intensive culture, it is necessary to establish a sense for knowledge as a competitive resource within the company. To provide a focus for organizational conversations on work, a common language must be established within the company, a language which is commonly shared and understood by the organizational members. The organizational structure needs to be implemented using an organizational design that facilitates knowledge development. e.g. to create an organization that works close to its customers and that has access to a variety of information that can be interpreted differently. This is believed to nurture creativity. (Ichijo et al. 1998.)

Helfat and Raubitschek (2000) have described a product sequencing model that consists of a system of knowledge (core and integrative knowledge) and a system of learning, including incremental learning (by doing and by using) and step-function learning (learning from ongoing feedback). They mention that core knowledge can form the foundation for multiple products and stages within vertical chains. Integrative knowledge is required for coordination of tacit knowledge and also complex and codified knowledge (consisting of several activities) within and across vertical chains of activities (ibid. 963-964).

Andreu and Ciborra (1996) discuss the role of core capabilities and organizational context in integrating knowledge exploration and exploitation into strategy (a strategic loop of core capabilities), capabilities (capabilities learning loop) and work practices (routine learning loop).

Hamel and Prahalad (1990) stress the importance of core corporate competencies as key issues in successful knowledge management. 
Active forms of facilitation can be seen as acquiring knowledge embedded in long-term physical resources - this implies experimenting, testing, exercising and simulating as goals towards for example mastering a production process. In processing tacit knowledge embodied in an experienced individual, a key element is shared experience. Acquiring tacit knowledge requires observation, imitation and practice (the step of socialization). Converting human-embodied knowledge to explicit knowledge implies narrating and using metaphors (the step of externalization). Then, processing an individual's embrained knowledge requires combining different bodies of knowledge held by individuals. The reconfiguring of existing embrained knowledge can be accomplished by sorting and adding, re-categorising, re-contextualizing and guided participation (the step of combination). Other ways of facilitating knowledge management could be job rotation, modelling, coaching, guidance, proximal guidance by an expert, and distal guidance. Finally, the acquisition of a community's embedded or encultured knowledge implies team-working, coaching and mentoring (Järvinen 2000; Nonaka 1994).

Knowing is a phenomenon that is manifest in systems of language, technology, collaboration and control (mediated). It is also located in time and space and is specific to particular contexts (situated). Knowing is constructed and constantly developing (provisional). It is also purposive and object-oriented (pragmatic). Finally, because of the interrelation of the concepts of knowledge and power, knowledge is also contested. Changes in the systems of knowing and doing are important. That is why attention should focus on the systems we are using to acquire information and knowledge. (Blackler 1995, 1039-1040.)

Knowledge creation and sharing are widely described as being based on individual learning (Kolb 1984) and also on team learning (Nonaka 1994; Kasl et al 1997). Kasl et al. (1997) speak about team learning as a five-step process involving framing (vision, goal and competence of the team), reframing (process to create shared understanding), experimenting (testing new frame and evaluation of the its function), crossing boundaries (information gathering and sharing with other members and groups) and integrating perspectives (combining view and ideas through discussion and conflicts). Crossan et al. (1999) have described the framework of organizational learning as starting from an individual, going on in the group, and ending up finally at the organizational level and creating a commercialized set of functions or issues. 
A Community can be an organization, team, group or partnership (some employees in a specific place or in a project or a time) or employees in meetings, or some friends, or any random person of a confrontation (including as well social and informal meetings when and wherever people are confronting each other in the company). The definition was ranked according to the internal closeness and co-operation degree of the unit. The unit itself can be also virtually organized locating anywhere anytime. (Brown and Duguid 1991; Boland and Tenkasi 1995.)

According to Senge (1990) the central issues in a learning organization are team-working, systemic thinking, models which lead thinking and functioning, and culture-supporting learning. The vision and goals, leadership, information management and output are also parts of the learning organization.

Essentially, all knowledge is directly or indirectly based on human resources and intellectual capital. The company must take care to develop and exploit this in order to become more effective and competitive. Knowing processes involve individuals, groups and teams, as well as the organization itself.

Finally, information can be described as being a part of explicit knowledge as a tool (knowing what) used by tacit knowledge (knowing how) in every day practices (knowing processes) in different circumstances (context), and all of these being inseparable from each other in knowledge creating, exploiting and sharing processes.

\subsection{Knowledge Sharing Processes}

Kolb (1984) describes individual learning in the four processes of concrete experience (as the starting point), active experimentation, abstract conceptualization and reflective observation. Some authors have been critical because of the model doesn't describe deeply enough reflective processes (Järvinen 2000). The model also seems to suppose that learning processes always begin from concrete experience even though it is possible to start learning by using explicit or implicit information as a spark or starting point. The context could also play a more essential role in the learning process of an individual.

Nonaka and Konno 1998 describe team and group learning in the four processes of socialization (as the starting point), externalization, combination and internalization during changes between tacit and explicit 
knowledge. In the model, the starting point is rather critical. It is also questionable to distinguish knowledge so sharply to explicit and tacit (implicit) parts, because it is necessary to use tacit knowledge to create explicit knowledge (Cook and Brown 1999; Wilson 2002; Hildreth and Kimble 2002).

The team learning model of Kasl et al. (1997) also sounds practical, using five steps: framing (starting point), reframing, experimenting, crossing boundaries and integrating perspectives.

The process of changing between tacit and explicit knowledge seems to be problematic, or even unnecessary to specify in practice (Cook and Brown 1999). Majchrzak et al. (2004) also refer to the importance of knowledge reuse for innovation.

Crossan et al. (1999) have created a framework of organizational learning, describing four processes including intuiting (as the starting point), interpreting, integrating and institutionalising and linking the three levels of individual, group and organization. The interest of the model of Crossan et al. lies in the renewal of the overall enterprise. The underlying and important issue and a principal means they cite is organizational learning. Renewal demands that organization has to investigate and learn new knowledge, exploiting things learned earlier in a similar way. They seem also to suppose that the process passes from intuiting to institutionalising.

All the three models have similarities in the number of processes involved. Even though the models have different levels for action (individual, group and organization) they have common interfaces between the actors. They seem to have an idea of systematic and at least partly continuing and mutual or commutual knowing processes.

Järvinen (2000) has integrated the three models, developing a synthesis of them. Based on these three models she has created a consolidated model with social, reflective, cognitive and working processes integrating individual, group and organizational levels. All these processes also have sub-processes drawn from the models of Kolb (1984), Nonaka and Konno 1998 and Crossan et al. (1999) and combined together.

Kim (1993) has defined and recognized several disconnects in learning processes. These learning disconnects could clarify more the interactions between relations of moving from one stage to another (e.g. institutionalizing of intuition). 
While Crossan et al. (1999) describe feed-forward and feedback processes, Kim focuses on single-loop and double-loop learning. A central issue in Kim's model seems to be the responses of the individual to environmental actions creating new learning.

Both models are based on experimental (individual) learning and adaptation and also assimilating of mental maps (individual and shared).

\subsection{Mental Maps of Knowing}

It should be noted that, while exploiting knowledge, there are cognitive maps in the background and these either impede or support the knowledge sharing processes in the organization (Kim 1993; Choo 1998). Employees have different mindsets, because of different motivation and commitment. An organizational mental map is created from its members' shared understanding about the organization's goals and ways to work (Robey et al. 2000). It therefore seems to be based on a common negotiated and accepted belief structure that has to be created in cooperation with employees and managers.

According to Kim (1993) a knowledge cycle occurs between individual actions and organizational routines as they influence the mental model of an individual - the organizational shared map also has an environmental response.

Robey et al. (2000) also describe organizational learning as cognitive entities capable of observing actions in order to improve performance. According to the authors, organizational improvement has much to do with organizational memory - defining it as a shared understanding of the members of an organization, the cognitive maps - connecting organizational actions to outcomes.

Brown and Duguid (1991) speak about canonical (formal) and noncanonical (informal) work practices based on a misunderstanding about what working, learning and innovation at work really are in practice. Narratives and story-telling have been used as a way to develop a causal map to bridge the gap between canonical and non-canonical - for example between what the company supplies and what a particular community actually needs. Shared narratives also point out collaborative aspects of work. It is also evident that, as a social construct, employees are strengthening their professional identities and becoming members of the image of 
professionalism. (ibid. 46-47.) Enacting and innovating can be conceived of as a fundamental sense-making and identity-building process (ibid. 53). To foster the whole development process, an organization must recognize itself as a community of communities. Conceptual reorganization to accommodate learning-while-working and innovation must stretch from the individual level to communities of practice and the technology to the level of the overarching organizational architecture, the community-of-communities (ibid. 55).

Crossan et al. (1999) also consider that what they call a mental map is the same as Kim's individual (and also organizational) mental models.

At the most basic level the relevant knowledge that permits effective communication both within and across subunits consists of shared language and symbols (Barney 1999).

\subsection{The Environment}

Learning and knowing processes seem to happen in special places. Nonaka and Konno (2000) use the term "Ba" to designate a suitable place to create and share knowledge in SECI-processes. These places can be face-toface or even virtual, where individuals share experiences, feelings, emotions and mental models.

Some offices use an architecture based on the concept of ' $\mathrm{Ba}$ ' - for example by placing the work stations of the employees around the recreation area. When employees have the time for recreation, they collect together. Information sharing processes start naturally. The bosses are placed among the employees, so that they can easily contact and communicate with each other when walking around. Thus the architecture of the workplace supports many opportunities for information sharing.

Virkkunen and Kuutti (2000) consider organizational learning as involving changes in management's assumptions. The main idea is that a practical and productive interaction can be developed through psychological processes. Individuals' actions are always an active system with a collective praxis. The activity system is internally heterogeneous and multi-voiced, including competing and conflicting things. The authors thus summarize organizational learning as a contextual, situational and historical process. To the present author, this all suggests an extended environment where places and their history constantly increase in significance for the future. 


\subsection{Tools Supporting the Acquisition, Creation, Use and Sharing of Knowledge}

It is important to look at the tools used for acquiring, using and maintaining information and knowledge (Huber 1990; Daft and Engel 1986). According to Johannessen et al. (2001), the mismanagement of IT and of tacit knowledge can lead to a company completely failing to benefit from the competitive advantages of IT. They argue that emphasizing IT by unilateral investments can lead to an underestimation of the tacit knowledge of the company. They point out that the relationship between tacit knowledge and IT is crucial. They discuss the management of the total knowledge base of the company (i.e., explicit and tacit knowledge) internally and externally. The role of IT is, according to them, improving and speeding accessibility to external (explicit) knowledge (ibid. 13).

According to Lee (1994, p 13) communication through electronic mail hides some essential information cues (body language, tones of voice) and does not support immediate feedback. This can be said about most information systems, because of the routine way in which they save information.

Robey et al. (2000) discuss the meaning and measurement of organizational learning, and focus on studying how to apply concepts to use and implement IT in organizations, as well as IT applications that support organizational learning. These themes are independent of each other although they have close conceptual and practical links. According to the authors, organizational learning stresses managerial vision, leadership, communication and teamwork. They also differentiate between organizational learning used as a mean to resolve and explain the problems of benefiting from new IT tools in organizations, and research that develops applications of IT to support the process of organizational learning and knowledge management. The capacity for organizational learning facilitates the adoption of IT that in turn increases the learning capacity of the organization.

Barney $(1991,114)$ mentions that information technology itself can be purchased easily whereas information processing systems are deeply embedded informal and formal processes of an organization - such systems store potential and are difficult to imitate. 


\subsection{Organizational Memory}

Cross and Baird (2000) studied learning in 22 projects covering different fields. Carrying out interviews across several hierarchical levels, they asked what had been learned and where knowledge was located within the organizations. They found out that an organization's memory (OM) resides in the minds of its employees (who were thus an important part of OM and thus a risk to lose), in the relationships between employees carrying out their work (the social network: who you know affects what you know), in databases and file cabinets (complementing personal networks supported by colleagues), embedded in work processes (methods embedded in recurring processes) and in product and service offering (developing experimental knowledge on the job; may also influence blind spots when changing).

Considering the steps involved in transforming experience into working knowledge the authors mention the need to determine which experiences are worth learning from (strategically important). Important learning events are often critical and most difficult to learn. The next step is to maximize learning potential - this includes providing a structure that encourages individuals and groups to reflect upon and share what they have learned. The final step is to embed into the organization the knowledge gained from enhanced experiences and building organizational memory. Thus, when individual learning occurs, the knowledge should be aggregated, validated and synthesized for organizational learning.

The authors point out that an important part of the organizational learning process is to learn about the backgrounds of individuals in groups and teams and also to develop knowledge about each other by focusing on task-based activities building harmony and providing opportunities for group members to demonstrate their skills and abilities. Communities of practices - informal groups of individuals integrating regularly around work-related issues and challenges - facilitate collaboration and learning from each other. In any case, what is most important is social bonding among the group's members. The authors mention that one of the greatest points of leverage in promoting organizational learning exists at the executive level. Again, it is important for the organization to ensure that learning is not forgotten when it occurs, but rather to fit and store it in the organizational memory.

Walsh and Ungson (1991) state that information is reducing equivocality. They distinguish decision-making information from stored information, called memory. Generally organizational memory is independent of particular individuals although individuals themselves acquire information as 
actors in the active construction of the memory. They exploit information based on decision-making process cumulating in an organizational memory of encoded and interpreted events with consequences. (ibid. 61-62).

The authors split organizational memory into information acquisition (decision making, problem-solving and their consequences), retention facilities (varying in their capacity to retain information) and information retrieval (varying from automated to controlled) and also refer to external archives.

According to Walsh and Ungson (1991) the retention facility of an organizational memory consists of five internal bins distributed across the organization. The first internal bin of organizational memory is individuals with articulated belief structure and cause maps, assumptions and their values.

A second bin is culture, which includes language, learned and transmitted feelings and even thinking, shared frameworks and stories, sagas and symbols.

Again, structure constructs the concept of a role as a link between individuals and organizational memories and also establishes links with environment. This includes implications for individual role behaviour and the reflection of the institutionalized myths of society as justified by members of an organization. Finally, ecology refers to the actual physical structure of the organization or of the workplace: the ecology encodes and retains information about the organization and its membership. (ibid. 63-66.)

An organizational memory plays important roles within organizations: it can be informational, it can fulfil a controlling function, and also play a political role (ibid. 73).

Regarding the misuses of organizational memory, the authors note that the automatic retrieval of information may support a routine response, even in cases where a non-routine response might have been better. (ibid. 75-77). The authors mention that individuals are a key in developing organizational memory because of they are a source of retained information and also determine the acquired and retrieved information in the organization.

It appears, thus, that there remains an open and very interesting question about the length, position and service role of the individual in the organization. The authors also note that there can be cases where there is a 
synthesis of organizational memory and organizational design in clans (a specific governance structure of members arising under conditions of bureaucratic failure) and in a network (a purposeful and conscious relationship between and among distinct organizations) facilitating the sharing of information (ibid. 80).

Organizational memory is widely known as an instrumental issue, but the extent to which non-routine information is deliberately stored to be used as a basis for future decision making is not well understood.

\subsection{Culture and Values}

Organizational culture can consist of belief-structures, values, ideals, norms and principles and also common ways of functioning. Organizational culture is created over long periods of time. It is typically hidden knowledge that is mostly tacit. It "learns" from the behaviour and genres of other employees. Culture can also change over time (Inglehart 1990.)

Taking care of relationships implies managing relationships between organizational members and fostering a culture that emphasizes patience and tolerance. Knowledge managers stimulate other managers to actively collect information, and to share information that penetrates different contexts for knowledge creation (e.g. new markets). (Ichijo et al. 1998.)

Functional and open organizational culture seems to support information and knowledge sharing by encouraging members to be active and to trust each others. This is an important issue of organizational knowledge structure.

\subsection{Framework of the Knowing Organization}

Thus, organizational learning occurs in the form of knowing processes (individual and collective, communities of practices). Furthermore, it needs to be managed and supported by tools and environmental factors. Finally, the learning process is going to create and develop an organizational memory that consists of common learning elements and tools, information acquisition, storing and distribution, individual and organizational relationships, products and services, mental maps, functional models and stories, which are enabled and supported by organizational culture and values. 


\section{CASE STUDY}

\subsection{Background}

Logistic Company is one of the most biggest logistics companies in Finland, with a turnover in 2003 of $1597 \mathrm{Me}$ and about 1700 employees. The company deals with the logistics of the delivery of products to customers throughout Finland, who buy them through its chain stores. The business idea is to use the logistics chain to deliver products from all over the world to its customers, with economies of scale producing the best price. Knowledgeable logistics employees are important assets in a successful business.

The work and duties in the logistics centre vary from gathering products by truck to work on computers. The logistics centre consists of two very big halls (with a size of about 13 football fields) and a dispatch department. In the logistics centre, fresh and dry products lines are received, gathered and combined for shops all over Finland. The stock in the logistics centre is huge and there is a busy stream of products. Work proceeds to implementation in three shifts in a complex and busy rhythm, demanding accuracy and cooperation. Certain perishable products are also dealt with in an unbroken cold chain to maintain quality. More than 600 trailer trucks visit the logistics centre every day (including weekends), unloading and loading cargo.

The most important function of the company is the core process of ordering and delivery. This starts with receiving and checking the products, moving them to the trucks (loading and unloading the shelves and moving products between different levels of shelves), providing the orders for gathering, gathering the products ordered, and finally transferring them to the dispatch department. The employees doing the gathering can plan and choose their own optimal gathering path. They also have to check and report about missing or understocked products by computer and order more for the shelves.

Similar processes apply in both product lines (fresh and dry goods). Clients can purchase products from both lines, and so both lines must work equally effectively for total success.

Although the employees work in groups, gathering and shelf work is mainly done individually. However, during gathering there are many occasions for a single employee to make the operation more effective by 
bearing in mind the needs of other gathering employees. She or he can provide information for other employees coming along later, which could help to speed up their work and the whole process. Reception and checking work also involve group work, where the benefits of information sharing can often be seen immediately.

\subsection{Some Findings}

Knowledgeable logistics employees are important in successful business possessing intellectual capital. Knowledge is situated in routines and processes (core and sub processes) and also in function models (concepts) that have been developed over long periods of time into working methods (Best Practices) and brought into information systems by staff. Of course products and services maintenance are important, but most products come from suppliers and so added value comes from managing logistic processes effectively. The employees tend to think that values and culture are not significant because they believe that values are only created for marketing purposes by managers.

Meanwhile "knowledge paths" have appeared among employees in the work processes and routines on the corridor, middle management (group/team knowledge) taking a stroll and walking among the employees. Top management staff have their own meetings and negotiating situations in which they consider the future facing the company as a whole and try to lead and fight for it as an entity. This creates the additional characteristic of knowledge in that it functions as a way of recognizing and empowering environmental issues for employees (empowered knowledge).

The present author considers that each level uses a different kind of knowledge that is not easy to integrate or exploit. The risk exists that the parties that are involved in knowledge sharing could be misunderstanding each other and losing information as it goes through organizational levels.

There are many places to share information and knowledge in the company. Meetings and negotiations are the most formal ways to gather, create, use and share knowledge. More informal places include discussions in the corridor and at refreshment points, coffee machines and restaurants. First impressions and feelings were often changed in working rooms. On the other hand, hobbies and friends circles were not so deeply or significant used. What is most important is connected with the practical information flows of the company. Gathering information by walking and meeting in the 
corridors and during working processes (e.g. the place where order lists are collected) also play a practical role.

Motivation and commitment are essential before anybody will want to share information and knowledge that she or he has. Some reasons for sharing are giving benefit to others, appreciating and exploiting information from others, resourcing and participating with others, natural idleness (with less activity leading to more sharing), learning through good experiences and to have more insight. Participating in common sharing processes can become activities which can motivate employees to share information among colleagues. This gives employees opportunities to bring up their own ideas and to participate in others' ideas. This starts the game of playing 'idea ball' with colleagues. Those who are passive won't be motivated to play, unless they participate officially. Some are more inclined to innovate than others, but they need to be encouraged to test themselves.

Equally, some employees are more inclined to follow routines, and to operate in unchanging and fixed styles, seeking internal satisfaction in other ways. It is also possible to derive personal benefit, and even financial profit, and at least to save time and trouble implementing one's own ideas and perceptions. Some employees may become inspired by their own ideas, but then guard them jealously. Others have no interest in developing ideas, reasoning that if an idea is not theirs, it is not worth implementing, and these employees can impede innovations. Finally, it is not enough to be successful oneself, if others are going to be unsuccessful. In such a situation, it is essential to be proactive.

Overall, the following methods have been used to share information and knowledge:

- intuiting, innovating, interpreting, integrating

- discussions

- recommendation

- persuading

- sharing ideas actively

- earlier experience

- participating

- introduction

- job rotation

- development discussions

- training

- support of colleagues. 


\subsection{Conclusions}

Most of the knowledge issues found in the literature can be seen functioning in the practices of the case study company. In addition, the present author would note the concept of physical "knowledge paths", and the issue of recognizing and integrating knowledge images at different hierarchical levels of the organization.

Each level of the organization uses different kinds of knowledge that are not easy to integrate or exploit. The real challenge is to integrate different kinds of knowledge modes and to understand, develop and exploit the integrated knowledge base.

Another problem that appeared was the poor resources of middle managers, some of whom were responsible for 30-40 employees. This leads to the situation where there is little time available to the manager and consequently few contacts between employees and managers. This is one of the important and critical issues. Some of the middle managers have solved the problem having 'daily walks' among employees. It is clear that initiative needs to be fostered among employees and a more flexible and systematic feedback system needs to be developed. At present, some of suggestions of the employees are not even replied to any way, decreasing motivation and activities.

Furthermore, an important question is who is leading and coordinating the whole process of developing the knowing environment. Human resources management (HRM) has been in the background, while operational managers implement what they can but only according their local goals. Thus HRM should play a more active role in knowledge management, creating HR processes and using HR tools (recruiting, familiarizing and mentoring, developing, teaching and compensating) with the cooperation of managers.

Information and knowledge sharing could be a part of everyone's duties. This would need to be supported by the values and culture of the company. It could be a challenge to increase resources for this purpose, and to recognize that it is important to place increased value on experience accumulated in the accumulating tacit knowledge of experienced and often ageing people.

The analysis of this case study is continuing, and future work will focus on the structure of communities of practice and the sharing of knowledge among them. 


\section{REFERENCES}

Andreu, Rafael and Ciborra, Claudio (1996) Organizational learning and core capabilities development: the role of IT. Journal of Strategic Information Systems Vol. 5, 111-127.

Barnley Jay B. (1991) Firm Resources and Sustained Competitive Advantage. Journal of Management Vol. 17 No. 1, 99-120.

Bonabeau,Eric and Theraulaz, Guy and Dorigo, Marco (1999) Swarm Intelligence - From Natural to Artifial Systems. Oxford University Press 1999. ISBN 0-19-513159-2.

Blackler, Frank (1995) Knowledge, knowledge work and organizations: An overview and interpretation. Organization studies 16.6. 1995, 1021-1046.

Boland R.J, and R.V. Tenkasi (1995), Perspective making and perspective taking in communities of knowing, Organization Science 6, No 4, 350-372.

Brown J.S. and P. Duguid (1991), Organizational learning and communities-of-practice: Toward a unified view of working, learning, and innovation, Organization Science 2, No $1,40-57$.

Castells, Manuel (1996) The Rise of the Networking Society. T.J. International Limited, Padstow, Cornwall. ISBN 1-55786-616-3.

Choo, Chun Wei (1998) Knowing organization. Oxford university press, 1998.

Cook. D. N and Brown John S. (1999) Bridging epistemologies: The GenerativeDance Between Organizational Knowledge and Organizational Knowing. Organization Science Vol. 10 No. 4 July - August 1999, pp. 381-400.

Cross Rob and Baird Lloyd (2000) Technology is not enough: Improving performance by building organizational memory. Sloan Management Review, Vol 41. Cambridge Spring 2000.

Crossan, Mary and Lane, Henry and White Roderick (1999) An organizational learning Framework: from intuition to institution. Academy of Management Review 1999, Vol. 24 No 3 522-537.

Daft R.L. and R.H. Lengel (1986), Organizational information requirements, media richness and structural design, Management Science 32, No. 5, 554-571.

Drucker, Peter E (1999) Knowledge-worker productivity: The biggest challenge. California Management Review, Vol. 41 No. 2, 1999, pp. 79-94.

Hamel and Prahalad (1990) The Core Competence of Corporation. Harward Business Review $68 / 1990$.

Hildreth, Paul and Kimble, Chris (2002) The Duality of Knowledge. Information Research, Vol. 8 No. 1, October 2002.

Holsapple, C.W and Joshi, K.D (2001) Organizational Knowledge Resources. Decision Support Systems 2001, Vol. 31 No. 1, 39-54.

Huber, George P. (1990) Organizational learning: The contributing processes and the literature. Organizational science February 1991 Vol. 2 No. 1, pp. 88-115.

Helfat, Constance E. and Raubitschek, Ruth S. (2000) Product sequencing: Co-evolution of knowledge, capabilities and products. Strategic Management Journal (2000), 21: 961-979.

Ichijo K., G. von Krogh and I. Nonaka (1998), Knowledge enablers, In von Krogh, Roos and Kleine (Eds), Knowing in firms - Understanding, managing and measuring knowledge, Sage, London, 173-203.

Inglehart, Ronald (1990) Culture shift in advanced industrial society. ISBN 0-691-02296-8.

Johannessen, Jon-Arild and Olaisen, Johan and Olsen Bjørn (2001) Mismanagement of tacit knowledge: the importance of tacit knowledge, the danger of information technology, and what to do about it. International Journal of Information Management (2001) No. 1, 21: 3 20 . 
Järvinen, Annikki (2000) Facilitating knowledge processing in a workplace setting. Presented in the $1^{\text {st }}$ international conference on Researching Work and Learning, 10.-12. September 1999, Leeds.

Kasl E., V.J. Marsick and K. Dechant (1997), Teams as learners - A research- based model of team learning, Journal of Applied Behavioral Science 33, No 2, 227-246.

Kim, Daniel. H (1993) The link between Individual and Organizational Learning. Sloan Management Review 1993, 37-50.

Kolb, David (1984) Experiential Learning. Experience as The Source of Learning and Development. Englewood Cliffs, N.J., Prentice-Hall 1984.

Lee, A.S (1994) Electronic mail as a medium for rich communication: an empirical investigation using hermeneutic interpretation. MIS Quarterly, 1994, 143-147.

Majchrzak, Ann and Cooper Lynne and Neece, Olivia, E. (2004) Knowledge Reuse for Innovation. Management Science Vol 50, No.2 February 2004, 174-188.

Masuda, Yoneji (1980) The Information Society as Post-Industrial Society. Betesda, USA 1980.

Nonaka, I (1994) A dynamic theory of organizational knowledge creation. Organization Sciences 5, No 1, 14-37.

Nonaka, I and Konno, N (1998) The Concept of 'BA'. Building a foundation for knowledge creation. California Management Review, Vol. 40 No. 3, 40-53.

Orlikowski, W (2000) Using technology and constituting structures: A practice lens for studying technology in organizations. Organization Science 11, No 4, 404-428.

Otala, Leenamaija (1997) Oppimisen etu-kilpailukykyä muutoksessa. Wsoy , Porvoo.

Robillard P.N (1999) The Role of Knowledge in software development. Comm. ACM 42 No. $1,87-92$.

Robey Daniel and Boudreau Marie-Claude and Rose Gregory M (2000) Information technology and organizational learning: a review and assessment of research. Accounting, Management and information Technology no. 10/2000 pp. 125-155.

Reich, Robert (1991) The Work of Nations.

Stehr, Nico (1994) Knowledge Societies. Sage publications Ltd 1994, London.

Stenberg, Martti (2000) From information into knowing - evaluating knowing of ageing employee. Helsingin yliopiston lahden tutkimus- ja koulutuskeskuksen raportteja ja selvityksiä 34/2000. Gummerus, Saarijärvi 2000. ISBN 951-45-8769-3.

Swanson, E.B (1994) Information Systems innovation among organizations. Management Science 40, No. 9 1069-1092.

Teece, David J (1998) Capturing Value from Knowledge Assets: The new Economy, Markets for Know-How, and Intangible Assets. California Management Review, Vol. 40 No.3, 1998.

Virkkunen J. and K. Kuutti (2000), Understanding organizational learning by focusing on "activity systems", Accounting, Management and Information Technology 10, No 4, 291 319.

Walsh, James. J and Ungson, Gerado R. (1991) Organizational memory. Academy of management Review 1991, Vol. 16 No. 1, 57-91.

Wilson, T.D (2002) The Nonsense of knowledge management'. Information Research,

Vol. 8 No. 1, October 2002.

Zuboff, $S$ (1988) In the age of the smart machine: The future of the work and power. New York: Basic books. 